\title{
Effects of Various Growth Regulators on in Vitro Rooting of Globe Artichoke (Cynara scolymus L.)
}

\author{
Nurgül Ercan \\ Department of Horticulture, Faculty of Agriculture, University of Akdeniz, Antalya 07059, Turkey
}

\begin{abstract}
Since micropropagation is useful tool to get healthy initial material, main target of many researches on this subject is to develop and/or optimize an efficient protocol for artichoke cultivars. In this study, influences of different doses of growth regulators indole-3-butyric acid (IBA), naphthalene acetic acid (NAA), gibberellin $\left(\mathrm{GA}_{3}\right)$ in combination with/without activated charcoal (AC), putrescine acid and jasmonic acid, added to Murashige and Skoog (MS) basal medium have been investigated on the rooting of globe artichoke (Cynara scolymus L.). Artichoke offshoots from 4-year-old mother plants of globe artichoke cultivars Sakiz and Bayrampaşa were used. Results showed that the highest rooting percentage $63.35 \%$ and $36.6 \%$ was obtained in Sakiz and Bayrampaşa, respectively, from the $5 \mathrm{mg} / \mathrm{L} \mathrm{GA}_{3}$ with $1 \mathrm{~g} / \mathrm{L} \mathrm{AC}$ added to MS medium.
\end{abstract}

Key words: Cynara scolymus L., growth regulators, root induction.

\section{Introduction}

Since vegetative parts of plants, such as offshoots, ovoli or batons, are used for propagation in artichoke cultivation, to find diseases-free initial material is very important issue. One of the ways of getting healthy plant material is micropropagation. In fact, besides obtaining only pathogen-free plants, this production has other benefits, such as cloning selection, ex situ conservation of local varieties or nursery production. Although in vitro multiplication is the best solution to obtain healthy material, difficulty in rooting of artichoke plantlets is the main obstacle that should be overcome. Because the root induction in vitro in artichoke is the critical stage, several investigations have been conducted on different cultivars and different growth regulators, such as indoleacetic acid (IAA), naphthaleneacetic acid (NAA), gibberellin $\left(\mathrm{GA}_{3}\right)$ in combination with/without activated charcoal (AC) [1-6]. According to previous researches, the success in root induction stage depends on genotype [7-9], and genotype specific protocols should be determined. López-Pérez and Martínez [9] reported

Corresponding author: Nurgül Ercan, professor, research field: vegetable growing. that the in vitro rooting was still the main subject to investigate especially in early artichoke cultivars mainly grown the Mediterranean region.

Sakiz and Bayrampaşa artichoke cultivars are the commercially grown, vegetatively propagated, old Mediterranean cultivars in Turkey. This present study was therefore conducted to determine in vitro rooting responses of Sakiz and Bayrampaşa artichoke cultivars to various growth regulators, including indole-3-butyric acid (IBA), NAA, GA3, putresine acid and Jasmonic acid with/without combination of AC added to Murashige and Skoog (MS) basal medium.

\section{Materials and Methods}

Artichoke offshoots (10-15 cm long) of Sakiz and Bayrampaşa cultivars were gathered from 4-year-old mother plants at Research Field of Akdeniz University, Faculty of Agriculture, during February and March, 2014. Off-shoots were washed with tap water, and then surface sterilized in $10 \%$ sodium hypo chloride solution added with 1-2 drop Tween-20 for $20 \mathrm{~min}$. The sterilized shoots were rinsed three times with sterilized distilled water for $5 \mathrm{~min}$. Shoot apices of 
8-10 $\mathrm{mm}$ in length were excised under a stereo microscope and placed on MS medium (Sigma, M 5519) [10] with $30 \mathrm{~g} / \mathrm{L}$ sucrose and $2.4 \mathrm{~g} / \mathrm{L}$ gelrite agar (Sigma G 1910). Before sterilization of the medium, $\mathrm{pH}$ was set at 5.7. Tubes were incubated at $25 \pm 1{ }^{\circ} \mathrm{C}$ with a $16 / 8 \mathrm{~h}$ dark-light period with 3,000 lux-light intensity provided by cool-white fluorescent tubes. In order to determine the effects of growth regulators and their combinations on rooting of artichoke, IBA (0.0, 0.1, 0.4, 0.8 and $1.0 \mathrm{mg} / \mathrm{L})$, NAA $(0.0,0.1,0.4,0.8$ and $1.0 \mathrm{mg} / \mathrm{L}), \mathrm{GA}_{3}(0,1,5$ and 10 $\mathrm{mg} / \mathrm{L}), \mathrm{GA}_{3}$ in combination with $\mathrm{AC}(1 \mathrm{~g} / \mathrm{L})$, jasmonic acid $(0,1,2.5$ and $5 \mathrm{mg} / \mathrm{L})$ and putrescine $(0,1,2.5$ and $5 \mathrm{mg} / \mathrm{L}$ ) were studied. Three replications with 10 shoots were employed for each medium. Plantlets were transferred to sterile peat-perlite mixture after root development. Experiments were performed on the basis of a completely randomized design. Data about rooting percentage were transformed before statistical analysis. ANOVA with Duncan's multiple range tests were performed.

\section{Results and Discussion}

\subsection{Effect of IBA on Rooting}

When IBA concentrations were taken into consideration, the highest number of roots per shoot, the longest root length and rooting percentage of both Sakiz and Bayrampaşa cultivars were recorded in MS medium supplemented with $0.4 \mathrm{mg} / \mathrm{L}$ IBA (Table 1), but rooting percentages was unsatisfactory in both cultivars. The highest rooting percentages were 33\% in Sakiz and $16.6 \%$ in Bayrampaşa. Because of lower or negative effects on rooting, IBA among the hormones used in rhizogenesis was scarcely used in artichoke. Lopez-Perez and Martinez [9] reported that rooting rates varied from $73.3 \%$ to $93.3 \%$ depending on cultivars, when $5 \mathrm{~d}$ darkness treatment on MS medium supplemented with $6 \mathrm{mg} / \mathrm{L}$ IBA. They emphasized that IBA in the culture medium without darkness treatment could be inadequate in rooting. Low rooting percentages found in this study could be explained by differences in IBA concentration, darkness treatment and genotype.

\subsection{Effect of NAA on Rooting}

Root induction was observed in all treatments of NAA, but was significantly higher when $0.4 \mathrm{mg} / \mathrm{L}$ NAA compared with the other concentrations (Table 2). It was determined that all NAA concentrations tested in this study promoted callus formation rather than rooting. Also in parallel to the increased concentrations of NAA, the increased callus formation was observed (data are not shown). Ancora et al. [11] reported that rooting rate was $58 \%$ when added $2 \mathrm{mg} / \mathrm{L}$ NAA to MS medium, while this rate was $33 \%$ when added $1 \mathrm{mg} / \mathrm{L}$ NAA. In contrast to the findings in this study, NAA was found effective on root induction in previous researches. Bigot and Foury [12] found $77 \%$ rooting in a culture medium containing $0.5 \mu \mathrm{M}$ NAA and $2 \mathrm{~g} / \mathrm{L}$ AC. Akinci and

Table 1 The effect of IBA concentrations on the mean number of roots per shoot, the longest root length and rooting ratio.

\begin{tabular}{lllll}
\hline Cultivars & IBA concentration $(\mathrm{mg} / \mathrm{L})$ & No. of roots/shoot & The longest root length $(\mathrm{cm})$ & Rooting $(\%)$ \\
\hline \multirow{4}{*}{ Sakiz } & 0.0 & $0.00^{\mathrm{e}}$ & $0.00^{\mathrm{d}}$ & $0.00^{\mathrm{e}}$ \\
& 0.1 & $1.03^{\mathrm{b}}$ & $1.22^{\mathrm{c}}$ & $0.66^{\mathrm{c}}$ \\
& 0.4 & $1.53^{\mathrm{a}}$ & $1.40^{\mathrm{a}}$ & $33.00^{\mathrm{a}}$ \\
& 0.8 & $0.88^{\mathrm{c}}$ & $1.32^{\mathrm{b}}$ & $20.00^{\mathrm{b}}$ \\
& 1.0 & $0.73^{\mathrm{d}}$ & $1.38^{\mathrm{a}}$ & $0.33^{\mathrm{d}}$ \\
\hline \multirow{4}{*}{ Bayrampaşa } & 0.4 & $0.00^{\mathrm{d}}$ & $0.00^{\mathrm{c}}$ & $0.00^{\mathrm{d}}$ \\
& 0.0 & $0.87^{\mathrm{b}}$ & $1.12^{\mathrm{b}}$ & $0.66^{\mathrm{c}}$ \\
& 0.8 & $1.07^{\mathrm{a}}$ & $1.22^{\mathrm{a}}$ & $16.60^{\mathrm{a}}$ \\
& 1.0 & $0.85^{\mathrm{b}}$ & $1.12^{\mathrm{b}}$ & $13.30^{\mathrm{b}}$ \\
\hline
\end{tabular}

${ }^{\mathrm{a}-\mathrm{e}}$ Means followed by the same letters are not significantly different at $P>0.05$. 
Table 2 The effect of NAA concentrations on the mean number of roots per shoot, the longest root length and rooting ratio.

\begin{tabular}{lllll}
\hline Cultivars & NAA concentration $(\mathrm{mg} / \mathrm{L})$ & No. of roots/shoot & The longest root length $(\mathrm{cm})$ & Rooting $(\%)$ \\
\hline \multirow{4}{*}{ Sakiz } & 0.0 & $0.00^{\mathrm{d}}$ & $0.00^{\mathrm{c}}$ & $0.00^{\mathrm{e}}$ \\
& 0.1 & $0.97^{\mathrm{c}}$ & $1.27^{\mathrm{b}}$ & $13.30^{\mathrm{c}}$ \\
& 0.4 & $2.21^{\mathrm{a}}$ & $1.82^{\mathrm{a}}$ & $20.00^{\mathrm{a}}$ \\
& 0.8 & $1.83^{\mathrm{b}}$ & $1.32^{\mathrm{b}}$ & $16.60^{\mathrm{b}}$ \\
\hline \multirow{6}{*}{ Bayrampaşa } & $1.62^{\mathrm{b}}$ & $1.29^{\mathrm{b}}$ & $10.00^{\mathrm{d}}$ \\
& 0.4 & $0.00^{\mathrm{d}}$ & $0.00^{\mathrm{c}}$ & $0.00^{\mathrm{e}}$ \\
& 0.1 & $1.83^{\mathrm{c}}$ & $1.83^{\mathrm{a}}$ & $0.33^{\mathrm{d}}$ \\
& 0.8 & $2.20^{\mathrm{a}}$ & $1.75^{\mathrm{a}}$ & $26.60^{\mathrm{a}}$ \\
& 1.0 & $1.97^{\mathrm{b}}$ & $1.35^{\mathrm{b}}$ & $13.30^{\mathrm{b}}$ \\
\hline
\end{tabular}

${ }^{\mathrm{a}-\mathrm{e}}$ Means followed by the same letters are not significantly different at $P>0.05$.

Abak [1] reported that the best results were obtained in $0.5 \mathrm{mg} / \mathrm{L}$ NAA for rooting stage.

\subsection{Effect of $G A_{3}$ on Rooting}

Effect of different $\mathrm{GA}_{3}$ concentrations on the mean number of roots per shoot, the longest root length and rooting ratio are presented in Table 3 . The highest number of roots per shoot, the longest root length and rooting percentage of both Sakiz and Bayrampaşa cultivars were recorded in MS medium supplemented with $5 \mathrm{mg} / \mathrm{L} \mathrm{GA}_{3}$.

The findings obtained from the present study revealed that rooting media added $\mathrm{GA}_{3}$ had positive impact in both cultivars taken to trial. Significant increases in examined criteria in this study were detected in parallel to the increase of $\mathrm{GA}_{3}$ concentration. According to the results, adding $\mathrm{GA}_{3}$ to the MS basal medium rather than auxins at rooting stage gave better results. The results are in accordance with the results of Morzadec and Hourtman [13], who reported addition of $\mathrm{GA}_{3}$ to the rooting medium also improved rooting percentage. Since the good results from the $\mathrm{GA}_{3}$ application were observed, the effect of the same $\mathrm{GA}_{3}$ concentrations in combination with 1 $\mathrm{g} / \mathrm{L}$ AC was searched (Table 4). Root number was found to be the highest with 7.15 in Sakiz and 6.73 in Bayrampaşa at $5 \mathrm{mg} / \mathrm{L} \mathrm{GA}_{3}$ concentration with $1 \mathrm{~g} / \mathrm{L}$ $\mathrm{AC}$ (Fig. 1). With increase in concentrations of $\mathrm{GA}_{3}$, the number of roots per shoot increased. The longest root length was $4.68 \mathrm{~cm}$ in Sakiz and $3.70 \mathrm{~cm}$ in
Bayrampaşa cultivars also at $5 \mathrm{mg} / \mathrm{L} \quad \mathrm{GA}_{3}$ concentration with presence of $1 \mathrm{~g} / \mathrm{L} \mathrm{AC} \mathrm{(Fig.} \mathrm{1).}$

\subsection{Effect of Putrescine and Jasmonic Acid on Rooting}

The effects of putrescine and jasmonic acid concentrations on the mean number of roots per shoot, the longest root length and rooting ratio are presented in Table 5. Since favorable results were not obtained in the Bayrampaşa variety due to contaminations, only Sakiz cultivar's results were given. The number of roots per shoot (1.55) and rooting rate (23.3\%) was the highest, when $5 \mathrm{mg} / \mathrm{L}$ putrescine acid were added to MS medium. The findings in this study are in agreement with the findings of Le Guen-Le Saos and Hourmant [14], who reported that application of exogenous putrescine with $0.5 \mathrm{mM}$ increased the percentage of rooting, but reduced the number of roots per plant.

Jasmonic acid has been added to the root induction medium in this research, since Martin-Closas et al. [15] reported the positive effects of methyl jasmonate on rooting of globe artichoke in traditional vegatative propagation. The number of roots per shoot and rooting rate was the highest, when $5 \mathrm{mg} / \mathrm{L}$ jasmonic acid was added to MS medium. However, the longest root obtained from the medium which contained 2.5 $\mathrm{mg} / \mathrm{L}$ jasmonic acid (Fig. 2).

After the acclimatization process, rooted plantlets of each cultivar were transferred to soil after 16 weeks (Fig. 3). According to the findings, plant survival ratio 

Globe Artichoke (Cynara scolymus L.)

Table $3 \mathrm{GA}_{3}$ concentrations on the mean number of roots per shoot, the longest root length and rooting ratio.

\begin{tabular}{lllll}
\hline Cultivars & $\mathrm{GA}_{3}$ concentrations $(\mathrm{mg} / \mathrm{L})$ & No. of roots/shoot & The longest root length $(\mathrm{cm})$ & Rooting $(\%)$ \\
\hline \multirow{4}{*}{ Sakiz } & 0.0 & $0.00^{\mathrm{d}}$ & $0.00^{\mathrm{d}}$ & 0.00 \\
& 1.0 & $2.42^{\mathrm{c}}$ & $2.32^{\mathrm{c}}$ & 13.30 \\
& 2.5 & $5.62^{\mathrm{b}}$ & $3.55^{\mathrm{b}}$ & 20.00 \\
& 5.0 & $6.53^{\mathrm{a}}$ & $4.05^{\mathrm{a}}$ & 56.60 \\
\hline \multirow{4}{*}{ Bayrampaşa } & 0.0 & $0.00^{\mathrm{d}}$ & $0.00^{\mathrm{d}}$ & 0.00 \\
& 1.0 & $1.88^{\mathrm{c}}$ & $2.23^{\mathrm{c}}$ & 26.60 \\
& 2.5 & $4.58^{\mathrm{b}}$ & $3.45^{\mathrm{b}}$ & 26.60 \\
\hline
\end{tabular}

${ }^{\mathrm{a}-\mathrm{d}}$ Means followed by the same letters are not significantly different at $P>0.05$.

Table $4 \mathrm{GA}_{3}$ concentrations in combination with $1 \mathrm{~g} / \mathrm{L} \mathrm{AC}$ on the mean number of roots per shoot, the longest root length and rooting ratio.

\begin{tabular}{lllll}
\hline Cultivars & $\mathrm{GA}_{3}$ concentrations $(\mathrm{mg} / \mathrm{L})$ & No. of roots/shoot & The longest root length $(\mathrm{cm})$ & Rooting $(\%)$ \\
\hline \multirow{4}{*}{ Sakiz } & 0.0 & $0.00^{\mathrm{d}}$ & $0.00^{\mathrm{d}}$ & 0.00 \\
& 1.0 & $2.52^{\mathrm{c}}$ & $2.55^{\mathrm{c}}$ & 16.60 \\
& 2.5 & $6.23^{\mathrm{b}}$ & $3.65^{\mathrm{b}}$ & 23.30 \\
& 5.0 & $7.15^{\mathrm{a}}$ & $4.68^{\mathrm{a}}$ & 63.30 \\
\hline \multirow{4}{*}{ Bayrampaşa } & 0.0 & $0.00^{\mathrm{d}}$ & $0.00^{\mathrm{c}}$ & 0.00 \\
& 1.0 & $2.08^{\mathrm{c}}$ & $2.13^{\mathrm{c}}$ & 26.60 \\
& 5.5 & $5.58^{\mathrm{b}}$ & $3.25^{\mathrm{b}}$ & 30.00 \\
\hline
\end{tabular}

${ }^{\mathrm{a}-\mathrm{d}}$ Means followed by the same letters are not significantly different at $P>0.05$.

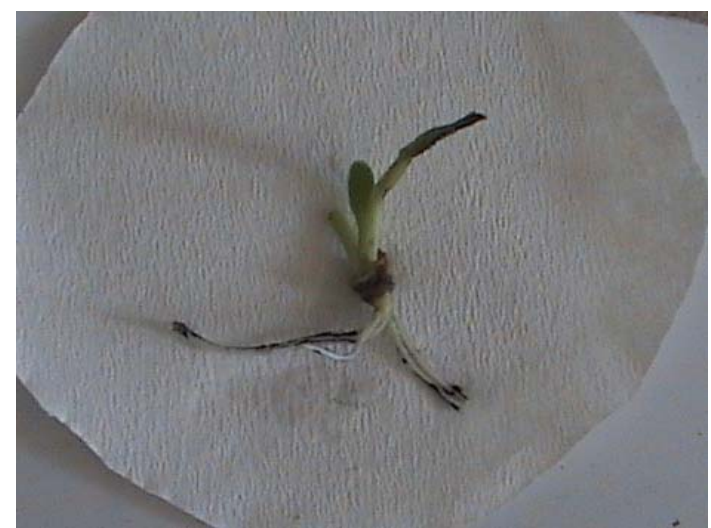

(a) Bayrampaşa

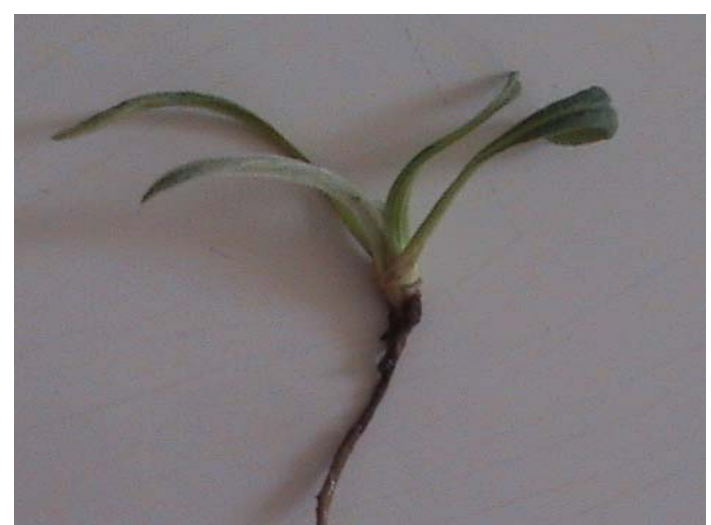

(b) Sakiz

Fig. 1 Rooted plantlet of Bayrampaşa (a) and Sakiz cultivar (b) from MS medium supplemented with 5 mg/L GA +1 g/L AC.

Table 5 The effects of putrescine and jasmonic acid concentrations on the mean number of roots per shoot, the longest root length and rooting ratio of Sakiz cultivar.

\begin{tabular}{lllll}
\hline Acid & Concentrations $(\mathrm{mg} / \mathrm{L})$ & No. of roots/shoot & The longest root length $(\mathrm{cm})$ & Rooting $(\%)$ \\
\hline \multirow{3}{*}{ Putrescine } & 0.0 & $0.00^{\mathrm{d}}$ & $0.00^{\mathrm{d}}$ & 0.00 \\
acid & 1.0 & $1.25^{\mathrm{c}}$ & $1.26^{\mathrm{b}}$ & 10.00 \\
& 2.5 & $1.48^{\mathrm{b}}$ & $1.48^{\mathrm{a}}$ & 16.60 \\
& 5.0 & $1.55^{\mathrm{a}}$ & $1.15^{\mathrm{c}}$ & 23.30 \\
\hline \multirow{5}{*}{ Jasmonic acid } & 0.0 & $0.00^{\mathrm{c}}$ & $0.00^{\mathrm{c}}$ & 0.00 \\
& 1.0 & $1.20^{\mathrm{b}}$ & $1.34^{\mathrm{b}}$ & 10.00 \\
& 2.5 & $1.22^{\mathrm{b}}$ & $1.63^{\mathrm{a}}$ & 20.00 \\
& 5.0 & $1.51^{\mathrm{a}}$ & $1.50^{\mathrm{a}}$ & 33.30 \\
\hline
\end{tabular}

\footnotetext{
${ }^{\mathrm{a}-\mathrm{d}}$ Means followed by the same letters are not significantly different at $P>0.05$.
} 


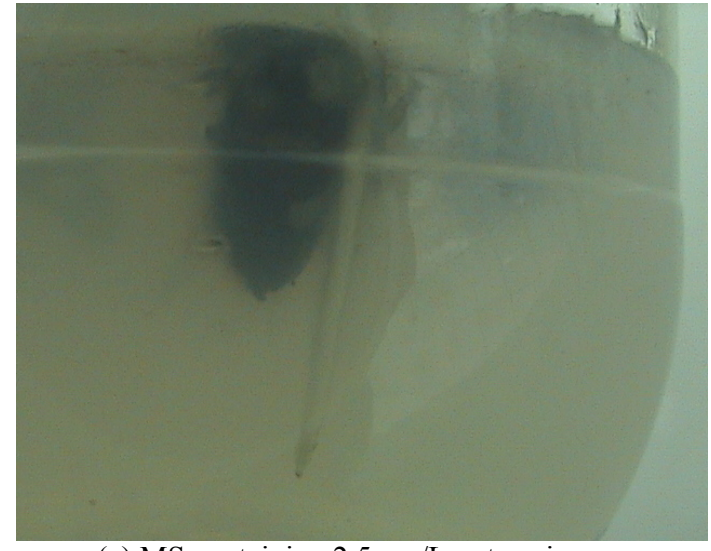

(a) MS containing $2.5 \mathrm{mg} / \mathrm{L}$ putrescine

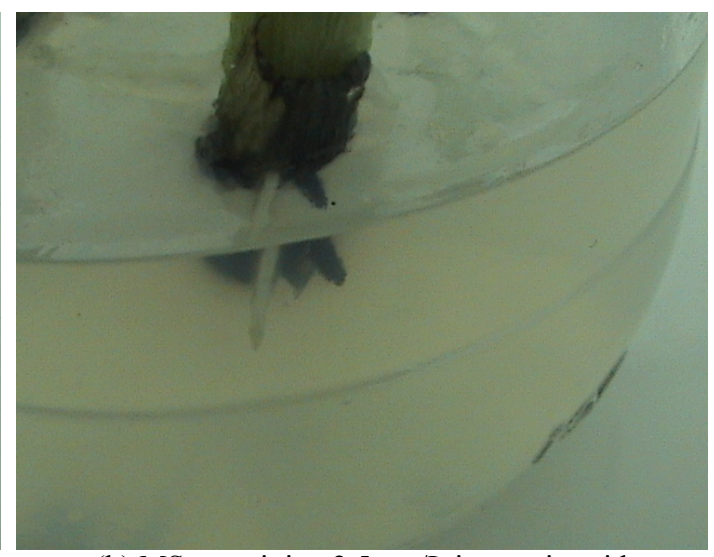

(b) MS containing $2.5 \mathrm{mg} / \mathrm{L}$ jasmonic acid

Fig. 2 Root formation of Sakiz cultivar at four weeks after transferring into MS medium containing $2.5 \mathrm{mg} / \mathrm{L}$ putrescine (a) and $2.5 \mathrm{mg} / \mathrm{L}$ jasmonic acid (b).
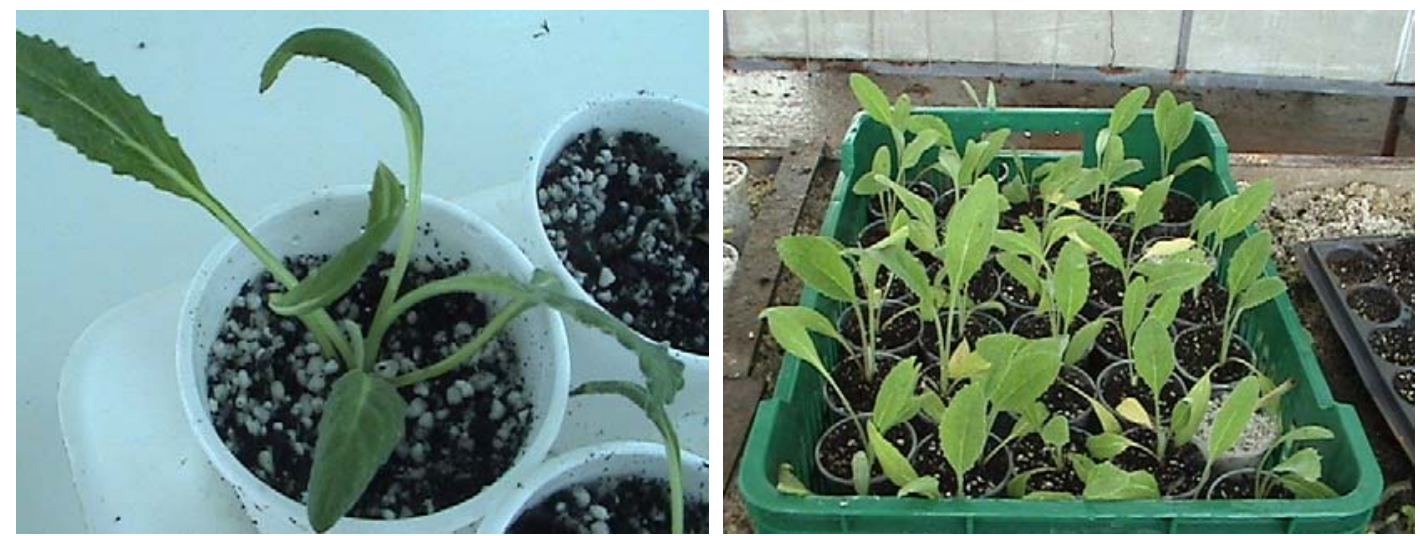

Fig. 3 Established plants grown in a greenhouse after acclimatization.

varied between $60 \%$ and $70 \%$ during acclimatization.

\section{Conclusions}

All concentrations of IBA and NAA tested in this study gave unsatisfactory results, compare to $\mathrm{GA}_{3}$ in terms of rooting. Although there were a few roots in plants, intense callus formation in the each auxin types was determined.

The results of the present study revealed that MS basal medium supplemented with $5 \mathrm{mg} / \mathrm{L} \mathrm{GA}_{3}$ and together with $1 \mathrm{~g} / \mathrm{L} \mathrm{AC}$ was found to be the best medium for rooting of the artichoke cultivars. Further studies are also needed to enhance rooting percentage for both cultivars, not only about nutrient composition but also donor plant age, some pretreatments to initial plant material, such as cold treatment, and incubation conditions such as darkness.

\section{References}

[1] Akinci, İ. E., and Abak, K. 1991. "The Effects of NAA and Kinetin Added to Nutrient Media on Stem Quantity and Quality of Globe Artichoke (Cynara scolymus L.) Producing by Meristem Culture." Turkish J. of Agriculture and Forestry 15: 248-59. (in Turkish)

[2] Brutti, C., Apostolo, N. M., Ferrarotti, S. A., Llorente, B. E., and Krymkiewicz, N. 2000. "Micropropagation of Cynara scolymus L. Employing Cyclodextrins to Promote Rhizogenesis." Scientia Horticulturae 83 (1): 1-10.

[3] Tavazza, R., Papacchiolli, V., and Ancora, G. 2004. "An Improved Medium for in Vitro Propagation of Different Cultivars of Globe Artichoke." Acta Horticulturae 660: 91-7.

[4] Cavallaro, V., Castiglione, V., Avola, G., and Fiocchiaro, E. 2004. "Influence of Different Substrates on the in Vitro Rhizogenesis Process of Early Artichoke (Cynara cardunculus L. subsp. scolymus (L.) Hegi)." Acta Horticulturae 660: 267-72.

[5] Elia, A., Conversa, G., Montervino, C., and Lotti, C. 
2007. "Micropropagation of the Early Artichoke Cultivar 'Violet Du Provence'." Acta Horticulturae 730: 127-34.

[6] Cavallaro, V., Trotta, F., Gennari, M., Di Silvestro, I., Pelegrino, A., and Barbera, A. C. 2013. "Effects of the Complex Nanosponges-Naphthalene Acetic Acid and $\beta$-Cyclodextrins on in Vitro Rhizogenesis of Globe Artichoke." Acta Horticulturae 983: 369-72.

[7] Bedini, L., Lucchesini, M., Bertozzi, F., and Graifenberg, A. 2012. "Plant Tissue Cultures from Four Tuscan Globe Artichoke Cultivars.” Cent. Eur. J. Biol. 7 (4): 680-9.

[8] El-Boullani, R., El-Moshli, A., El-Finti, A., El-Mousadik., A., and Serghini, M. A. 2013. "Effect of Decapitation and Size of Explants on in Vitro Multiplication Rate of Globe Artichoke." Acta Horticulturae 983: 325-9.

[9] Lopez-Perez, A. J., and Martinez, J. A. 2015. "In Vitro Root Induction Improvement by Culture in Darkness for Different Globe Artichoke Cultivars." In Vitro Cell. Dev. Biol.-Plant 51 (2): 160-5.

[10] Murashige, T., and Skoog, F. A. 1962. "A Revised Medium for a Rapid Growth and Bio Assays with Tobacco Tissues Cultures." Physiologia Plantarum 15 (3): 473-97.
[11] Ancora, G., Belli-Donini, M. L., and Cuozzo, L. 1981. "Globe Artichoke Obtained from Shoot Apices through Rapid in Vitro Micropropagation." Scientia Horticulturae 14: 207-13.

[12] Bigot, C., and Foury, C. 1984. "In Vitro Propagation of Globe Artichoke (Cynara scolymus L.) from Seedlings: Field Comparison of Some Clones with Their Parent Lines.” Agronomie 4 (8): 699-710. (in French)

[13] Morzadec, J. M, and Hourmant, A. 1997. "In Vitro Rooting Improvement of Globe Artichoke (cv. Camus de Bretagne) by $\mathrm{GA}_{3}$." Scientia Horticulturae 72 (1): 59-62.

[14] Le Guen-Le Saos, F., and Hourtmant, A. 2001. "Stimulation of Putrescine Biosynthesis via the Ornithine Decarboxylase Pathway by Gibberellic Acid in the in Vitro Rooting of Globe Artichoke (Cynara scolymus)." Plant Growth Regulation 35 (3): 277-84.

[15] Martin-Closas, L., Toro, F. J., Calvo, G., and Pelacho, A. M. 2004. "Effect of Methyl Jasmonate on the First Developmental Stages of Globe Artichoke." Acta Horticulturae 660: 185-90. 